\title{
FETAL GROWTH, GESTATION LENGTH AND PHOSPHOGLUCOMUTASE-1 PHENOTYPE
}

\author{
FRANK D. JOHNSTONE ${ }^{* \dagger}$, JOHN D. WEST ${ }^{\dagger}$, ROBIN J. PRESCOTT $\$$, JUDITH M. STEEL $\ddagger$, \\ JEAN A. FLOCKHART ${ }^{\dagger}$, IAN A. GREER ${ }^{\dagger}$, GUIDO A. DRAGOIl AND DAVID B.WHITEHOUSEIl \\ ${ }^{\dagger}$ Department of Obstetrics and Gynaecology, University of Edinburgh, Centre for Reproductive \\ Biology, 37 Chalmers Street, Edinburgh, EH3 9EW

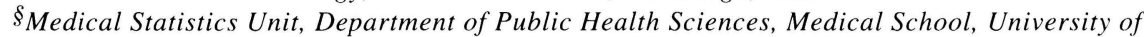 \\ Edinburgh, Teviot Place, Edinburgh, EH8 9AG \\ $¥$ Department of Diabetes, Royal Infirmary, Lauriston Place, Edinburgh, EH3 9YW \\ IIMRC Human Biochemical Genetics Unit, The Galton Laboratory, Wolfson House, University \\ College London, 4 Stephenson Way, London, NWl $2 H E$
}

\begin{abstract}
SUMMARY
This study investigates reports that phosphoglucomutase-1 (PGM1) phenotype is associated with fetal growth and gestation length. A total of 350 women were studied, 234 having uncomplicated pregnancies and 114 with a baby weighing greater than 90th centile, corrected for parity, gestation and fetal sex. All women had gestation confirmed by early ultrasound. Conventional cellulose acetate electrophoresis was used to distinguish the three common PGM1 phenotypes and polyacrylamide gel isoelectric focusing to distinguish the ten PGM1 subtypes. Neither PGM1 phenotype nor subtype were found to be associated with gestation length or standardised birth weight. Logistic regression, where maternal age, parity, fetal sex, maternal weight, gestation and smoking were introduced as explanatory variables in addition to PGM1 phenotype testing against the dependent variables birth weight, standardised birth weight and gestation length, did not show differences related to PGM1 phenotype.

Two possible reasons for the discrepancy with previously published data are discussed. We conclude that the study provides no support for the belief that PGM1 phenotype is related to fetal growth or gestation length and that the original observations could have arisen as a result of statistical artefact due to multiple testing.
\end{abstract}

KEYwords: Pregnancy Fetus Growth Gestation Macrosomia Phosphoglucomutase

\section{INTRODUCTION}

Control of fetal growth and timing of delivery are two key issues in obstetrics. Both are of great clinical significance, but remain poorly understood. It is recognised that the same individual woman tends to repeat fetal size and gestation length and that there is a strong maternal genetic component. However, this has not been defined.

An Italian group have reported the effect of genetic polymorphisms on these two aspects of human reproduction (Bottini et al. 1979, Bottini et al. 1985, Gloria-Bottini

* Correspondence to: Dr F D Johnstone, Department of Obstetrics and Gynaecology, University of Edinburgh, Centre for Reproductive Biology, 37 Chalmers Street, Edinburgh EH3 9EW, U.K., Telephone: 031229 2575, Fax: 0312292408 
et al. 1986, Lucarini et al. 1987, Gloria-Bottini et al. 1988, Amante et al. 1990). One of the most powerful associations was with phosphoglucomutase (PGM1) phenotype. Phosphoglucomutase (EC 5.4.2.2) is a phosphotransferase which catalyses the interconversion of glucose-1-phosphate and glucose-6-phosphate, an essential step in carbohydrate metabolism. Four separate loci determine distinct sets of PGM isozymes: PGM1, PGM2, PGM3 and PGM4. However 85 - 95\% of total PGM activity is determined by the PGMI locus in most human tissues (McAlpine et al. 1970). PGMl is polymorphic and has been widely used in testing for disease association, population genetics and forensic science. Conventional electrophoresis distinguishes the three common PGM1 phenotypes (PGM1 1, PGM1 2 and PGM1 2-1) produced by the two common alleles (Spencer et al. 1964) while iso-electric focusing has subsequently demonstrated that the three common phenotypes can be sub-divided into 10 phenotypes involving 4 rather than 2 common PGMI alleles (Bark et al. 1976, Kuhnl et al. 1977, Sutton and Burgess 1978).

Bottini et al. (1979) claimed that homozygosity (for either of the two PGMI alleles distinguished by electrophoresis) decreased intra-uterine growth rate. The association of maternal PGM1 2 phenotype with light for dates babies was particularly strong. Subsequently, Gloria-Bottini et al. (1986) showed an association between maternal PGM1 phenotype and birth weight $(\mathrm{P}=0.005)$. There was also a relationship with duration of gestation (with shorter gestation length in women with PGM1 2 phenotype; $\mathrm{P}=0.02$ ) and correlation analysis showed that about $5 \%$ of the variance in duration of gestation depended on genetic variability of maternal PGM1. These observations were confirmed by Lucarini et al. (1987) who studied a larger series and again showed a highly significant relationship between PGM1 phenotype and both birth weight and gestation length.

Two hypotheses would explain these findings. The first relates to the functional difference between enzyme activities. Scacchi et al. (1983) showed that activity associated with PGM1 2 is greater than that associated with PGM1 1 (110.5: 100). Although the in vitro difference was relatively slight, Gloria-Bottini et al. (1986) suggest that the difference may be amplified under stressed metabolic situations such as pregnancy and may then have an effect on the variability of intra-uterine development. The alternative hypothesis is that $P G M I$ is closely linked to a gene on chromosome 1 which is involved in fetal growth and development and that there is linkage disequilibrium between these two loci.

Because of the obvious importance for perinatal events and also possible effects on the development of adult disease, we set out to examine the relationship PGM1 phenotype has with fetal growth and gestation length by studying a larger population, by defining gestational age more accurately, by taking into account other factors associated with fetal size, and by investigating sub groupings of PGMl phenotype in more detail with isoelectric focusing.

\section{METHODS}

\section{Subjects}

A total of 350 women were studied in two groups. Group 1 comprised 234 pregnancies in women without pre-existing medical or pregnancy complications. These women were approached at an ante natal clinic. Group 2 comprised 114 
pregnancies where the woman had delivered a baby weighing $>90$ th centile, corrected for parity, gestation and fetal sex (Forbes et al. 1982). These women had no medical complications and were defined retrospectively, generally being approached within 3 days of delivery.

All women had gestation confirmed by early pregnancy ultrasound. Where menstrual data were uncertain or cycle was irregular, ultrasound estimate of gestation was used. Where menstrual data were acceptable, gestation was defined by last menstrual period providing that ultrasound estimate did not differ by more than 7 days. Where this latter case applied, gestation was defined by ultrasound dating.

The study was explained in general terms to each woman, and blood was taken with patient consent. The study was approved by the local Medical Ethics Committee.

\section{Sample Preparation}

White cells were prepared from 6mls of blood by Ficoll-Paque (Pharmacia) gradient centrifugation according to the manufacturer's instructions and stored in approximately $10 \mu \mathrm{l}$ of supernatant at $-20^{\circ} \mathrm{C}$ for up to one week. After PGM1 typing by conventional cellulose acetate electrophoresis (below), any remaining sample was stored at $-70^{\circ} \mathrm{C}$ or in liquid nitrogen. Red cell pellets were prepared for PGM1 sub-typing from two lml samples of blood and washed twice with isotonic saline. They were stored at $-70^{\circ} \mathrm{C}$ or in liquid nitrogen until they were shipped (packed in dry ice) to the MRC Human Biochemical Genetics Unit for analysis by isoelectric focusing.

\section{Cellulose Acetate Electrophoresis}

Conventional cellulose acetate electrophoresis was used to distinguish the three common phosphoglucomutase-1 phenotypes (PGM1 1, PGM1 2 and PGM1 2-1) as described fully elsewhere (Johnstone et al. 1994). Briefly, electrophoresis was performed in duplicate on Helena Titan III plates, using two different buffer systems ( $\mathrm{pH}$ 8.1-8.5 Tris-glycine and $\mathrm{pH}$ 8.6 Tris EDTA-borate). PGM1 activity was visualised as blue bands after incubation of the cellulose acetate plates with a filter paper overlay soaked with the staining solution.

\section{Isoelectric focusing}

The ten PGM1 subtypes were distinguished by polyacrylamide gel isoelectric focusing (IEF) as described by Whitehouse et al. (1989). Gels ( $240 \times 100 \times 0.4 \mathrm{~mm})$ were made from $87 \%$ glycerol, 2ml; acrylamide/bis-acrylamide 29:1 (Bio-Rad), 1.5ml: riboflavin $(\mathrm{mg} / 100 \mathrm{ml}), 1.5 \mathrm{ml}$ and approximately $2.5 \% \mathrm{w} / \mathrm{v} \mathrm{LKB} \mathrm{Ampholines;} \mathrm{deionised} \mathrm{water} \mathrm{to}$ $15 \mathrm{ml}$. Contact between the gel and electrodes was made with filter paper wicks (Whatman No 17) soaked in $1 \mathrm{M} \mathrm{H}_{3} \mathrm{PO}_{4}$ (anode) and $\mathrm{IM} \mathrm{NaOH}$ (cathode). Gels were pre-focused at $300 \mathrm{~V}$ for 30 minutes, focused for 30 minutes at $300 \mathrm{~V}$ and then for $3.5 \mathrm{~h}$ at $2000 \mathrm{~V}(8 \mathrm{~mA}$, $10 \mathrm{~W})$. Samples were applied to the gel near the anode, in $6 \times 4 \mathrm{~mm}$ pieces of filter paper at the beginning of the focusing period and the filter papers were removed after $1 \mathrm{~h}$. Following isoelectric focusing, the PGM1 activity was detected by incubating the gel with an agar overlay containing the reaction mixture, as described by Harris and Hopkinson (1976).

\section{Statistical Methods}

One way analysis of variance has been used to compare the lengths of gestation 
between the PGM1 phenotypes. Other comparisons among the phenotypes or alleles are based on the chi- squared test, with Yates' continuity correction applied where appropriate. In some tables this test is applied despite the numbers being lower than usually considered necessary for its application. The effect of low numbers is to give a falsely increased chance of a significant result, but as our results are non-significant, the low numbers do not invalidate our conclusions. Missing values have not been specifically identified in the tables and where totals do not agree, this is because of incomplete information.

\section{RESULTS}

Only pregnancies from our Group 1 women, recruited prospectively, are considered initially (Tables 1-5). The observed phenotype frequencies from conventional electrophoresis are shown in relation to gestation length in the form displayed by Gloria-Bottini et al. (1986) in Table 1. No differences in gestation length were found in the different phenotype groups. The same information is presented for sub groups delineated by isoelectric focusing in Table 2. No differences in gestation length were found between the different sub groups.

The observed phenotype frequencies from conventional electrophoresis are shown in relation to birth weight centile in the form displayed by Gloria-Bottini et al. (1986) in Table 3. No differences in proportions of babies in the different centile birth weight categories were found. The same information for phenotype sub groups also does not show any differences (Table 4).

Table 5 shows the result of logistic regression where maternal age, parity, fetal sex, maternal weight, maternal height, gestation and smoking were introduced as explanatory variables in addition to PGM1 phenotype testing, against the dependant variables birthweight, standardised birth weight and gestation length. No differences related to PGM1 phenotype were found.

Table 6 shows a comparison of phenotype distribution in 143 women with a pregnancy where the baby weighed $>90$ th centile and 201 women with a pregnancy where the baby weighed $\leq 90$ th centile. This includes women from our group 2 , selected retrospectively because of macrosomia. No differences in phenotype distribution by conventional electrophoresis (Table 6) or by iso-electric focusing (Table 7) were found. When these cases are included in linear logistic regression, as described above, PGM1 phenotype still did not contribute significantly to the regression (analysis available on request).

\section{DISCUSSION}

This study has shown no evidence for the claims by Bottini et al. (1979) Gloria-Bottini et al. (1986) and Lucarini et al. (1987) that PGM1 phenotype is strongly related to birth weight and length of gestation. Indeed, not only was there no statistically significant relationship, but there were no trends in the anticipated directions. Thus the second two papers reported that macrosomia was significantly more common in PGM1 2 women but our series (Table 6) shows a marginally lower percentage of macrosomic babies in this group. The first two papers described light for dates babies occurring more commonly in PGM1 2 women, but Table 3 shows a marginally lower percentage of such babies in women of this phenotype. Gloria-Bottini et al. (1986) and Lucarini et 
Table 1. Duration of Gestation in Relation to Maternal PGM1 phenotype

\begin{tabular}{cccc}
\hline & $\begin{array}{c}\text { Duration of } \\
\text { Gestation } \\
\text { Maternal PGM1 } \\
\text { phenotype }\end{array}$ & $\begin{array}{c}\text { S.D. Value } \\
\text { (weeks) }\end{array}$ & $\begin{array}{c}\text { No. of } \\
\text { Newborn } \\
\text { infants }\end{array}$ \\
\hline 1 & 39.4 & 1.5 & 145 \\
$2-1$ & 39.5 & 1.6 & 72 \\
2 & 39.9 & 0.5 & 17 \\
\hline
\end{tabular}

Significance of differences in gestation $\mathrm{P}=0.45$

Table 2. Duration of Gestation in Relation to Maternal PGM1 sub-type

\begin{tabular}{|c|c|c|c|}
\hline $\begin{array}{c}\text { Maternal PGM1 } \\
\text { phenotype }\end{array}$ & $\begin{array}{l}\text { Duration of } \\
\text { Gestation } \\
\text { Mean Value } \\
\text { (weeks) }\end{array}$ & S.D. & $\begin{array}{c}\text { No. of } \\
\text { Newborn } \\
\text { infants }\end{array}$ \\
\hline $1+$ & 39.4 & 1.5 & 97 \\
\hline $1+1-$ & 39.4 & 1.4 & 44 \\
\hline $1-$ & 39.0 & 0.0 & 2 \\
\hline $2+1+$ & 39.8 & 1.3 & 43 \\
\hline $2+1-$ & 39.9 & 0.9 & 7 \\
\hline $2-1+$ & 39.0 & 2.1 & 18 \\
\hline $2-1-$ & 38.0 & 1.7 & 3 \\
\hline $2+$ & 39.7 & 0.5 & 11 \\
\hline $2+2-$ & 40.2 & 0.4 & 5 \\
\hline $2-$ & 40.0 & - & 1 \\
\hline
\end{tabular}

Significance of differences in gestation, $\mathrm{P}=0.36$

al. (1987) observed that gestation length was shortest in PGM1 2 women whereas in our data there was no such trend (Table 1).

Our study did have advantages from a methodological point of view. A larger population was studied, with a total of 234 pregnancies compared with 93 (Bottini et al. 1979), 138 (Gloria-Bottini et al. 1986) and 201 (Lucarini et al. 1987) pregnancies, and a much higher number of macrosomic babies were studied with a total of 143 compared with 21 (Gloria Bottini et al. 1986, and Lucarini et al. 1987). There 
Table 3. Centile birth weight in relation to maternal PGM1 phenotype

\begin{tabular}{ccccc}
\hline \multirow{2}{*}{$\begin{array}{c}\text { PGM1 } \\
\text { phenotype }\end{array}$} & $<10$ & $10-90$ & $>90$ & Total \\
\cline { 2 - 4 } 1 & 9 & 117 & 18 & 144 \\
$2-1$ & 9 & 51 & 12 & 72 \\
2 & 1 & 14 & 2 & 17 \\
Total & 19 & 182 & 32 & 233 \\
\hline
\end{tabular}

Pearson chi square shows no association between centile birthweight and PGM1 phenotype. $\chi^{2}=3.78 \quad($ df 4$) \quad P=0.44$

was careful documentation of factors which could affect birth weight, and this allowed examination of any independent effect of PGM1 phenotype. Gestation was defined more accurately with confirmation in every case by ultrasound performed in early pregnancy. Sub groupings of PGM1 phenotype were examined to test whether there were tighter associations with any of the sub types detected by isoelectric focusing.

The study has ample power to detect relationships of the order described by the Italian group. The failure to do so matches our failure (Johnstone et al. 1994) to confirm work by the same group suggesting a different, but strong influence of PGM1 phenotype on macrosomia in diabetic pregnancy (Bottini et al. 1985, Lucarini et al. 1987, Bottini et al. 1988, Gloria-Bottini et al. 1989, 1994). There are two explanations for the discrepancy between results.

The first possibility is that the Italian and Scottish populations have different frequencies of $P G M 1 * 1$ and $P G M 1 * 2$ alleles. It is possible that, because of such a difference, PGM1 phenotypes could emerge as a factor affecting birth weight and gestation in Italy but not Scotland. Table 8 shows that our study had a higher proportion of PGM1 1 phenotypes and, consequently, our population had a slightly higher proportion of $P G M I * I$ alleles than two Italian studies. This difference, between our population and that of the larger of the two Italian studies (Lucarini et al. 1987), is statistically significant $(\mathrm{P}=0.04)$. Although the phenotype ratio in our study fitted Hardy-Weinberg expectations less exactly than the other studies shown in Table 8, the observed ratio was not significantly different from the predicted one (observed, 145:72:17; expected, $\left.140: 82: 12 ; \chi^{2}=3.47\right)$. The possibility that larger samples might reveal a characteristic difference between the Italian and British populations was tested but no statistically significant difference was found (Table 9). However, our present control population had a higher proportion of $P G M I * I$ than the combined Italian data and this difference was statistically significant at the 5\% level (Table 9). Nevertheless, the magnitude of the difference is small and it seems unlikely that the slightly higher proportion of $P G M 1 * 1$ alleles in our series would prevent us from detecting relationships of the order described by the Italian group. 
Table 4. Centile birth weight in relation to maternal PGM1 sub type

\begin{tabular}{|c|c|c|c|c|}
\hline \multirow{2}{*}{$\begin{array}{c}\text { PGM1 } \\
\text { phenotype }\end{array}$} & \multicolumn{3}{|c|}{ Centile birth weight } & \multirow[b]{2}{*}{ Total } \\
\hline & $<10$ & $10-90$ & $>90$ & \\
\hline $1+$ & 6 & 79 & 11 & 96 \\
\hline $1+1-$ & 2 & 35 & 7 & 44 \\
\hline $1-$ & 0 & 2 & 0 & 2 \\
\hline $2+1+$ & 5 & 31 & 7 & 43 \\
\hline $2+1-$ & 0 & 6 & 1 & 7 \\
\hline $2-1+$ & 4 & 10 & 4 & 18 \\
\hline $2-1-$ & 0 & 3 & 0 & 3 \\
\hline $2+$ & 0 & 11 & 0 & 11 \\
\hline $2+2-$ & 1 & 2 & 2 & 5 \\
\hline $2-$ & 0 & 1 & 0 & 1 \\
\hline Total & 18 & 180 & 32 & 230 \\
\hline
\end{tabular}

Pearson chi square shows no association between centile birthweight and PGM1 subtype. $\chi^{2}=19.33 \quad($ df 18$) \quad P=0.37$

If the predisposition to macrosomia was caused, not by PGM1 itself, but by a closely linked locus on chromosome 1 , it would be necessary to invoke allelic association between the "macrosomia allele" at the second locus and $P G M I * 1$. Although it might be possible for strong allelic association to occur in the Italian, but not in the Edinburgh population, this seems extremely unlikely.

The second possibility is that a statistically significant association could initially have been observed by chance if multiple statistical testing had been performed on observed effects of many different markers on many different outcomes, without a prior hypothesis. As discussed in our assessment of effects in diabetes (Johnstone et al., 1994), literature search through Index Medicus disclosed 26 papers from the group on such markers with end points related to pregnancy or early child development (list available on request). At least 11 marker systems (including PGM1) and at least 14 outcome variables (such as birthweight) were studied; some variables have sub divisions, while some studies analyse effects by maternal and paternal 
Table 5. Regression of Birthweight, Standardised Birth Weight and Gestation on possible explanatory variables including PGM1 status.

\begin{tabular}{|c|c|c|c|c|c|c|}
\hline \multirow{3}{*}{$\begin{array}{l}\text { Explanatory } \\
\text { Variable }\end{array}$} & \multicolumn{6}{|c|}{ Coefficient (SE) } \\
\hline & \multicolumn{6}{|c|}{ Dependent Variable } \\
\hline & \multicolumn{2}{|c|}{$\begin{array}{l}\text { Birthweight } \\
\text { (g) }\end{array}$} & \multicolumn{2}{|c|}{$\begin{array}{l}\text { Standardised } \\
\text { Birthweight }\end{array}$} & \multicolumn{2}{|c|}{$\begin{array}{c}\text { Length of } \\
\text { Gestation (weeks) }\end{array}$} \\
\hline Constant term & \multicolumn{2}{|r|}{-6540} & \multicolumn{2}{|r|}{-11.85} & \multicolumn{2}{|c|}{33.67} \\
\hline Maternal age (years) & -0.1 & $(5.8)$ & 0.000 & $(0.014)$ & 0.001 & $(0.021)$ \\
\hline Parity & 72.3 & $(31.0)^{*}$ & 0.085 & $(0.075)$ & -0.006 & $(0.111)$ \\
\hline Fetal sex $($ male $=1$, female $=2)$ & -93.6 & $(53.0)$ & 0.106 & $(0.128)$ & -0.213 & $(0.188)$ \\
\hline Maternal weight (kg) & 3.3 & $(3.0)$ & 0.007 & $(0.007)$ & 0.017 & $(0.011)$ \\
\hline Maternal height (cms) & 14.5 & $(4.2)^{* * *}$ & 0.038 & $(0.010)^{* * *}$ & 0.032 & $(0.015)^{*}$ \\
\hline Gestation (weeks) & 190.7 & $(19.9)^{* * *}$ & 0.136 & $(0.048)^{* *}$ & - & - \\
\hline Smoking (number per day) & -10.9 & $(4.3)^{*}$ & -0.020 & $(0.010)^{*}$ & -0.007 & $(0.015)$ \\
\hline PGM1 2-1 (diff. from 1) & -69.7 & $(59.0)$ & -0.116 & $(0.142)$ & 0.022 & $(0.210)$ \\
\hline PGM1 2 (diff. from 1) & -130.7 & $(101.6)$ & -0.312 & $(0.245)$ & 0.335 & $(0.361)$ \\
\hline Sig. level for PGM1 & \multicolumn{2}{|c|}{$\mathrm{P}=0.28$} & \multicolumn{2}{|r|}{$\mathrm{P}=0.38$} & \multicolumn{2}{|c|}{$\mathrm{P}=0.65$} \\
\hline
\end{tabular}

Table 6. Macrosomia (birth weight $>90$ th Centile) in relation to maternal PGM1 phenotype, including women with macrosomia defined retrospectively.

\begin{tabular}{lccc}
\hline \multirow{2}{*}{$\begin{array}{l}\text { PGM1 } \\
\text { phenotype }\end{array}$} & \multicolumn{2}{c}{ Centile birth weight } & \\
\cline { 2 - 3 } 1 & 126 & $>90$ & Total \\
\hline $2-1$ & 60 & 87 & 213 \\
2 & 15 & 48 & 108 \\
& & 8 & 23 \\
Total & 201 & 143 & 344 \\
\hline
\end{tabular}

Pearson chi square shows no association between macrosomia and PGM1 phenotype. $\chi^{2}=0.85 \quad($ df 2$) \quad P=0.65$ 
Table 7. Macrosomia (birth weight $>90$ th Centile); in relation to maternal PGM1 subtype, including women with macrosomia defined retrospectively.

\begin{tabular}{lrrr}
\hline \multirow{2}{*}{$\begin{array}{l}\text { PGM1 } \\
\text { subtype }\end{array}$} & \multicolumn{2}{c}{ Centile birth weight } & Total \\
\cline { 2 - 3 } $1+$ & 85 & 59 & 144 \\
$1+1-$ & 37 & 25 & 62 \\
$1-$ & 2 & 3 & 5 \\
$2+1+$ & 36 & 30 & 66 \\
$2+1-$ & 6 & 6 & 12 \\
$2-1+$ & 14 & 12 & 26 \\
$2-1-$ & 3 & 0 & 3 \\
$2+$ & 11 & 2 & 13 \\
$2-2+$ & 3 & 5 & 8 \\
$2-$ & 1 & 1 & 2 \\
Total & 198 & 143 & 341 \\
\hline
\end{tabular}

Pearson chi square shows no association between macrosomia and PGM1 subtype.

$\chi^{2}=9.01 \quad($ df 9$) \quad P=0.44$

genotypes separately and also independently include the effect of fetal sex. The potential number of associations examined, without necessarily a prior hypothesis, is extremely large.

This type of search procedure is useful to generate a hypothesis which can then be examined specifically in a new, completely independent population. Statistical testing in this population then rests on classical examination of the null hypothesis. Whether this has been done is unclear. Gloria-Bottini et al. (1986) refer simply to "a consecutive series of 142 women who were delivered of a single liveborn infant". Lucarini et al. (1987) describe "a consecutive series of 201 women from the population of Rome who were delivered of a single liveborn infant". No details are given and it is possible that the same cases are included in each study. If this is true, then the independent data from the study by Lucarini et al. (1987) obtained by subtraction from the earlier study, do not support the relationship between PGM1 phenotype and macrosomia, or with gestational length.

The claims in the papers referred to are not entirely consistent. Bottini et al. (1979) claimed that there was an excess of PGM1 2 and a reduction in PGM1 2-1 phenotypes in mothers with light for dates babies. These claims were not confirmed by Gloria- 
Table 8. Comparison of PGM1 phenotype distributions and PGM1 allele frequencies in different populations.

\begin{tabular}{|c|c|c|c|c|c|c|c|}
\hline \multirow[t]{2}{*}{ Series $\dagger$} & \multirow{2}{*}{$\begin{array}{l}\text { No. of } \\
\text { samples }\end{array}$} & \multicolumn{3}{|c|}{ PGM1 Phenotype Distribution } & \multicolumn{2}{|c|}{ Number of allelest† } & \multirow{2}{*}{$\begin{array}{c}\text { Frequency of } \\
\qquad P G M 1 * 1 \\
\text { allele }(\%)\end{array}$} \\
\hline & & 1 & $2-1$ & 2 & $P G M 1 * 1$ & $P G M 1 * 2$ & \\
\hline Gloria-Bottini & 138 & 72 & 54 & 12 & 198 & 78 & 71.74 \\
\hline Lucarini & 201 & 101 & 85 & 15 & 287 & 115 & 71.39 \\
\hline Edinburgh & 234 & 145 & 72 & 17 & 362 & 106 & 77.35 \\
\hline \multicolumn{8}{|c|}{ Statistical comparison of $P G M I$ allele frequencies ( $\chi^{2}$ test) } \\
\hline \multirow{2}{*}{\multicolumn{3}{|c|}{$\begin{array}{l}\text { Edinburgh versus Gloria-Bottini } \\
\text { Edinburgh versus Lucarini }\end{array}$}} & $\chi^{2}=2.94$ & & & \multirow{2}{*}{\multicolumn{2}{|c|}{$\begin{array}{l}P=0.09 \\
P=0.04\end{array}$}} \\
\hline & & & $\chi^{2}=4.05$ & & & & \\
\hline
\end{tabular}

$\dagger \quad$ Data from Gloria-Bottini et al. (1986), Lucarini et al. (1987) and present series of control patients with normosomic babies (data from Table 1)

$\dagger \dagger \quad P G M 1 * 1$ allele frequency is calculated from the phenotype frequencies: (2xPGM1 1)+PGM1 2-1 $P G M 1 * 2$ allele frequency is calculated from the phenotype frequencies: (2xPGM1 2)+PGM1 2-1

Bottini et al. (1987). This latter study found an excess of PGM1 2 phenotype pregnancies where the baby was macrosomic, and found phenotypes PGM1 2-1 and PGM1 2 to be associated with the longest and shortest gestations respectively. These findings were confirmed by Lucarini et al. (1987) but it is not clear that this population was independent, as discussed above.

In conclusion, our study provides no basis for the belief that PGM1 phenotype is related to fetal growth or gestation length. It seems possible that the original observations arose as a result of statistical artefact due to multiple testing.

\section{ACKNOWLEDGEMENTS}

We are grateful to Birthright for financial support. G.A.D was supported by a grant from the Home Office. We thank M. Compton, and M.Hensey for expert technical assistance and Mrs W. Hepburn for data processing help.

\section{REFERENCES}

Amante, A., Gloria-Bottini, F., Bottini, E. (1990). Intrauterine growth: association with acid phosphatase genetic polymorphism. J. Perinat. Med., 18, 275-282

Bargagna, M., Abbagnale, L. (1982). Isoelectric focusing of human red cell phosphoglucomutase $\left(\mathrm{PGM}_{1}\right)$. Phenotype distribution in the population of Tuscany and two hereditary variants. Hum. Genet., 61, 242-245. 
Table 9. Comparison of PGM1 allele frequencies in different populations.

\begin{tabular}{|c|c|c|c|c|}
\hline \multirow[t]{2}{*}{ Series $\dagger$} & \multirow{2}{*}{$\begin{array}{c}\text { No. of } \\
\text { samples }\end{array}$} & \multicolumn{2}{|c|}{ Number of alleles } & \multirow{2}{*}{$\begin{array}{c}\text { Frequency of } \\
P G M 1 * 1 \\
\text { allele }(\%)\end{array}$} \\
\hline & & $P G M I * 1$ & $P G M 1 * 2$ & \\
\hline British 1 & 123 & 184 & 62 & 74.79 \\
\hline British 2 & 329 & 491 & 167 & 74.61 \\
\hline Total British & 452 & 675 & 229 & 74.67 \\
\hline Italian 1 & 589 & 865 & 313 & 73.43 \\
\hline Italian 2 & 519 & 734 & 304 & 70.71 \\
\hline Total Italian & 1108 & 1599 & 617 & 72.16 \\
\hline \multicolumn{5}{|c|}{ Statistical comparison of $P G M 1 * 1$ allele frequencies $\left(\chi^{2}\right.$ test) } \\
\hline Total British & Total Italian & $\chi^{2}=2.05$ & d.f. $=1$ & $\mathrm{P}=0.15$ \\
\hline Edinburgh $+\dagger$ & Total British & $\chi^{2}=1.20$ & d.f. $=1$ & $\mathrm{P}=0.27$ \\
\hline Edinburght† & Total Italian & $\chi^{2}=5.30$ & d.f. $=1$ & $\mathrm{P}=0.02$ \\
\hline
\end{tabular}

$\dagger \quad$ Data for British 1 (Bark et al., 1976), British 2 (Welch et al., 1979), Italian 1 (Cortivo et al., 1984) and Italian 2 (Bargagna and Abbagnale, 1982) were taken from a summary table in Seetan et al., 1986. The proportions of $P G M I * 1$ and $P G M I * 2$ were calculated by adding the proportions of $P G M 1 * 1^{+}$and $P G M 1 * 1^{-}$or $P G M 1 * 2^{+}$and $P G M 1 * 2^{-}$ respectively. The allele frequency proportions were converted to actual numers for statistical tests by multiplying by the total number of alleles in the population (twice the number of samples).

$\dagger+$ Edinburgh data is from Table 8 .

Bark, J.E., Harris M.J., Firth, M. (1976). Typing of the common phosphoglucomutase variants using isoelectric focusing - A new interpretation of the phosphoglucomutase system. J. Forens. Sci. Soc., 16, 115-120.

Bottini, E., Gerlini, G., Fallucca, F., Lucarini, N., Bonci, E., Arachi, S., Gloria-Bottini, F. (1985). Diabetic pregnancy: fetal development and maternal phosphoglucomutase phenotype. Disease Markers, 3, 83-89.

Bottini, E., Gerlini, G., Pascone, R., Gori, M.C., Gloria-Bottini, F. (1988) Is there a role of chromosome 1 in the clinical expression of diabetes mellitus? Am. J. Hum. Genet., 43, $217-$ 219 
Bottini, E., Gloria-Bottini, F., Lucarelli, P., Polzonetti, A., Santoro, F., Varveri, A. (1979) Genetic polymorphisms and intrauterine development: evidence of decreased heterozygosity in light-for-dates human newborn babies. Experientia, 35, 1565-1567.

Cortivo, P., Biasiolo, M., Scorretti, C., Caenazzo, L., Beneciolini, P. (1984). The PGM1 polymorphisms as revealed by ultrathin-layer isoelectric focusing in the population of Padua. Forensic Sci Int., 24, 169-172.

Forbes, J.F., Smalls, M.J., Cole, S.K. (1982) Centile values of birthweight for gestational age in Scottish infants 1975-1979. Social Paediatric and Obstetric Research Unit, University of Glasgow.

Gloria-Bottini, F., Gerlini, G., Lucarini, N. (1988) Fetal macrosomia and erythrocyte acid phosphatase (ACP1) polymorphism in diabetic and normal pregnancy. Early Hum. Dev., 17, 265-274.

Gloria-Bottini, F., Gerlini, G., Lucarini, N., Borgiani, P., Gori, M.C., Amante, A. and Bottini, E (1989) Enzyme polymorphisms and clinical variability of diseases: a study of diabetes mellitus. Hum. Biol., 61, 571-589.

Gloria-Bottini, F., Gerlini, G., Lucarini, N., Amante, A., Lucarelli, P., Borgiani, P., Bottini, E. (1994). Both maternal and foetal genetic factors contribute to macrosomia of diabetic pregnancy. Hum. Hered., 44, 24-30.

Gloria-Bottini, F., Lucarini, N., Bonci, E., Pascasio, F., Bonci, M., Assumma, M., Scalamandrè A, Bottini, E. (1986). Genetic polymorphism and intrauterine development: the role of maternal PGM 1 and MNSs genotypes. Am. J. Dis Children, 140, 324-326

Harris H., Hopkinson D.A. (1976). Handbook of Enzyme Electrophoresis in Human Genetics. North Holland Publishing Company, Amsterdam.

Johnstone, F.D., West, J.D., Steel, J., Whitehouse, D.B., Drago, G.A., Greer, I.A., Prescott, R.J. (1994). Lack of association between maternal phosphoglucomutase-1 phenotype and fetal macrosomia in diabetic pregnancy. Br. J Obstet and Gynaecol., 101, 239-245.

Kuhnl, P., Schmmidtmann, U., Spielmann, W. (1977). Evidence for two additional common alleles at the PGM1 locus (Phosphoglucomutase - EC 2.7.5.1.). A comparison by three different techniques. Human Genetics, 35, 219-223.

Lucarini, N., Gerlini, G., Gloria-Bottini, F., Gori, M.C., Borgiani, P., Caprella, M.L., Bottini, E. (1987) Fetal macrosomia in diabetic pregnancy. Further data on the association with maternal PGM1 genotype. Diabetes Research, 5, 169-174.

McAlpine, P.J ., Hopkinson, D.A., Harris, H. (1970). The relative activities attributable to the three phosphoglucomutase loci $\left(\mathrm{PGM}_{1}, \mathrm{PGM}_{2}, \mathrm{PGM}_{3}\right)$ in human tissues. Ann. Hum. Genet., 34, 169-175,

Scacchi, R., Corbo, R.M., Palmarino, R., Sacco, G., Arnone, M., Lucarelli, P. (1983). Human phosphoglucomutase locus 1: Red cell enzymatic activities associated with common isoelectric focusing phenotypes. Hum Hered., 33, 218-222.

Seetan, I.M., Funayama, M., Sagisaka, K. (1986). Red cell phosphoglucomutase (PGM 1$)$ subtypes in Egyptians. Forensic Science International, 31, 55-59

Spencer, N., Hopkinson D.A., Harris, H. (1964). Phosphoglucomutase polymorphism in man. Nature, 204, 742-745.

Sutton, J.G., Burgess, R. (1978). Genetic evidence for four common alleles at the phosphoglucomutase-1 locus $\left(\mathrm{PGM}_{1}\right)$ detectable by isoelectric focusing. Vox Sang, 34, 97-103.

Welch, S.G., Wood, N.J., Dodd, B.E. (1979). Red cell PGM1 (phosphoglucomutase) phenotyping by isoelectric focusing and starch gel electrophoresis in cases of disputed paternity in the United Kingdom. An evaluation of the results obtained in 95 cases. Forensic Science International, 13, 87-92.

Whitehouse, D.B., Drago, G.A., Hopkinson, D.A., Westwood, S.A., Werrett, D.J. (1989). Immunological detection of human phosphoglucomutase (PGM1) subtypes. Forensic Sci. Internat., 41, 25-34. 


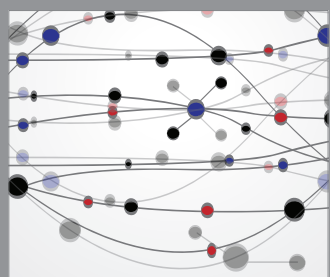

The Scientific World Journal
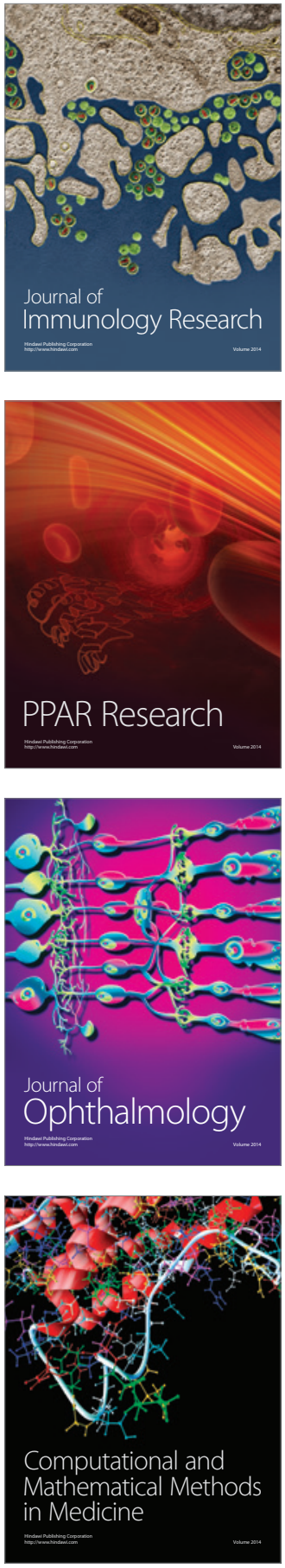

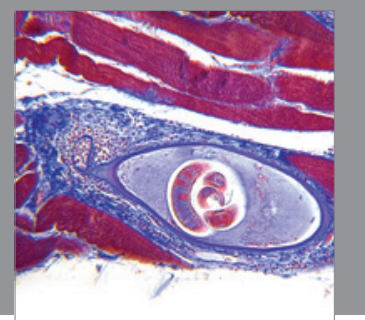

Gastroenterology

Research and Practice
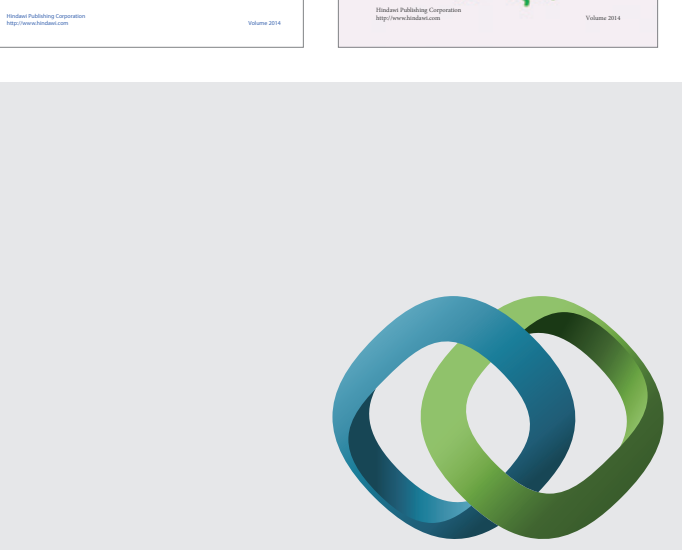

\section{Hindawi}

Submit your manuscripts at

http://www.hindawi.com
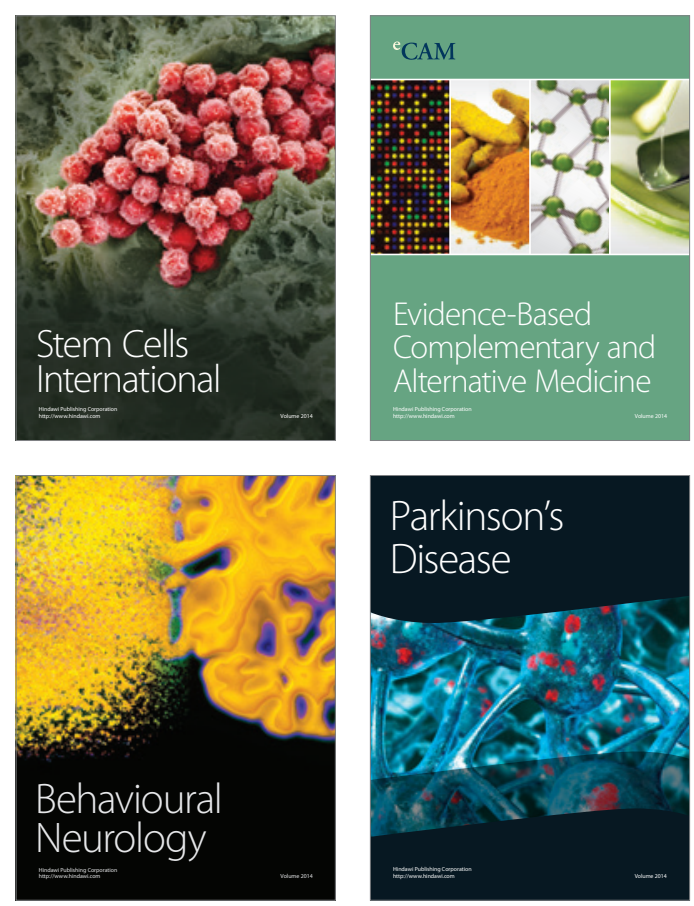

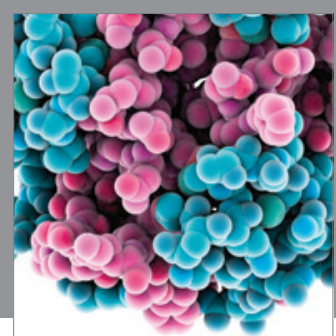

Journal of
Diabetes Research

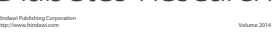

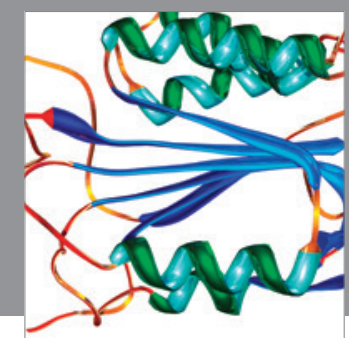

Disease Markers
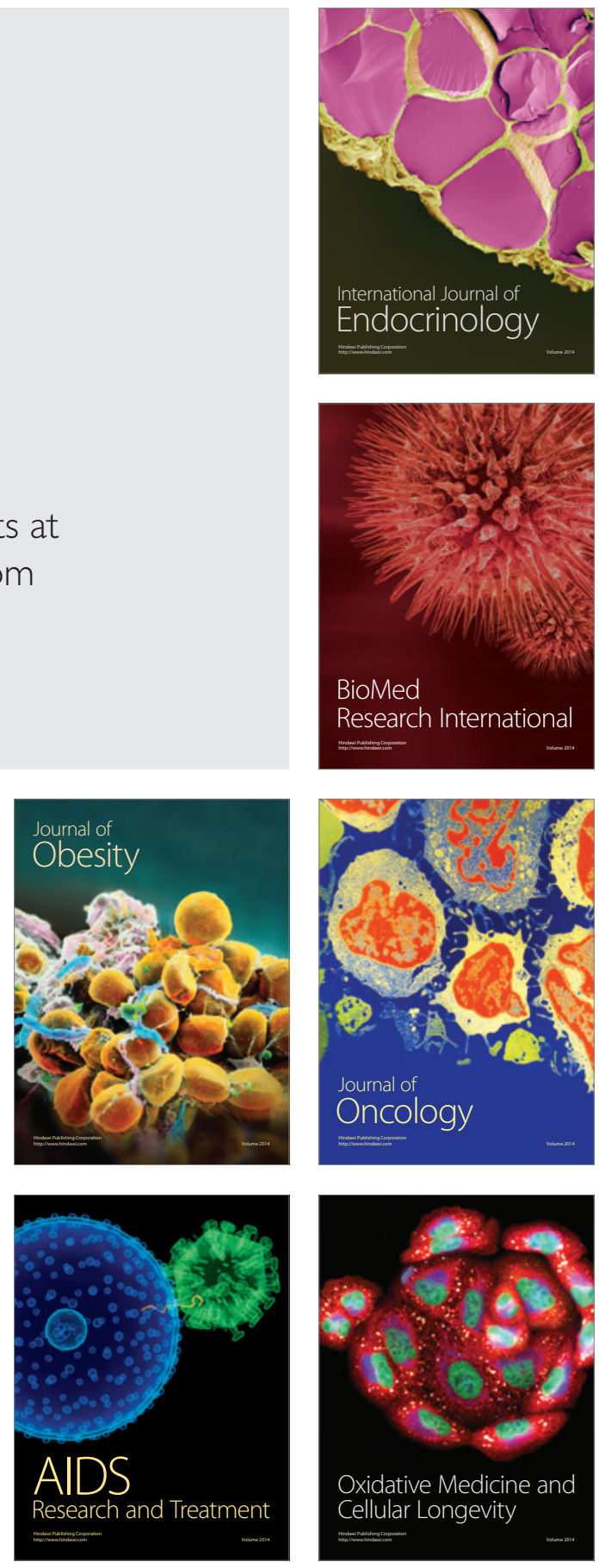